\title{
TOPONIMIA INDÍGENA DE LA PROVINCIA DE GUANACASTE, COSTA RICA
}

\author{
Flor Garita Hernández
}

\begin{abstract}
RESUMEN
En este estudio se hace una clasificación de los topónimos indígenas de la provincia de Guanacaste, Costa Rica, según la lengua de procedencia. La mayoría de topónimos son nombres comunes y un número muy reducido procede de nombres propios, en sus lenguas de origen. También se analizan algunas etimologías y estructuras gramaticales.
\end{abstract}

\begin{abstract}
This study presents a classification of Indian language toponyms of the province of Guanacaste, according to the source language. The analysis includes toponyms derived from common names and the few derived from proper names. Also included are a number of etimologies and grammatical structures.
\end{abstract}

\section{Introducción}

En este trabajo se presentan los nombres topónimos de la provincia de Guanacaste, Costa Rica, provenientes de lenguas indígenas. Para su clasificación se ha seguido el modelo propuesto en "Toponimia de la provincia de Cartago" (Garita 1995). El estudio no pretende ser exhaustivo en cuanto a las etimologías de lenguas indígenas, sino que, principalmente se establece la lengua indígena de donde proceden, se aclaran algunas etimologías y significados y se clasifican en nombres provenientes de la fauna, de la flora u otros, según las preferencias culturales de los hablantes. Se analizan, además, desde el punto de vista de la gramática española, las estructuras gramaticales.

Para la información sobre etimologías y significados se toma como base el Diccionario de la Real Academia y a partir de ahí, los vocablos que no registra esta obra se buscan en los diferentes diccionarios especializados de costarriqueñismos, americanismos, diccionarios etimológicos, o bien de obras sobre léxico español. También, como metodología de trabajo, se entrevistó al investigador Quesada Pacheco en lo relativo a la ubicación de algunos nombres polémicos que, según su opinión, pertenecen al chorotega, pese a que otros autores los han ubicado como nahuas o aztecas. 


\section{Poblamiento precolombino de la provincia}

De acuerdo con De la Cruz (1988), tradicionalmente se ha considerado a Costa Rica dividida en dos grandes grupos lingüísticos: los grupos del Pacífico Norte (Golfo de Nicoya, Península de Nicoya, Valle del Tempisque y el norte de Guanacaste), de filiación mesoamericana y los grupos del resto del país (Llanuras del Norte, Región Atlántica, Pacífico Central y Sur) de filiación macrochibcha. La división de dos sectores culturales en Costa Rica, dice Ferrero Acuña, puede apreciarse en las técnicas agrícolas que los españoles notaron en el siglo XVI y que eran utilizadas por los aborígenes. En muchos aspectos la prehistoria de Costa Rica es un modelo de coexistencia de varios modos de agricultura: cultivos de granos en un lado; en otro, predominio de la vegecultura, y en otros combinación de ambos. Esto se refleja en los sistemas de subsistencia y por ende en otros aspectos de su cultura.

El Pacífico Norte o Región de Guanacaste estuvo habitado por los chorotegas o mangues y los nicaraos de habla nahua. La presencia de estos indígenas en El Salvador, Nicaragua y Costa Rica se debió a la presión que ejercieron sobre ellos pueblos como los toltecas, los aztecas y otros del centro de México. Los grupos se desplazaron de México hacia Nicaragua entre los siglos VIII y XIII d. C. y se establecieron en Guanacaste a partir del siglo XIII, cuando llegaron a Rivas las migraciones de los nicaraos. Convivieron en la región con otras etnias con las que establecieron relaciones recíprocas en arte, comercio, religión y economía. El área de habitat de los chorotegas y de los nicaraos se ha denominado la Gran Nicoya, considerada como una parte de Mesoamérica. Es posible que antes de la influencia mesoamericana, el Pacífico Norte pudiera haber estado habitado por pueblos afines a los del resto del país.

Los asentamientos del Pacífico Norte, por lo menos en el momento de la conquista, debieron seguir los patrones mesoamericanos: una plaza central y alrededor casas rectangulares, cada una con un uso especial. Entre ellas se encontraban los palacios donde vivían el cacique y los principales. Otras se destinaban para las mujeres del cacique, otras para los guerreros y otras para el almacenamiento del maíz y para la cocina.

Respecto de la vida diaria, la cultura en términos generales posee muchísimos rasgos de la cultura de México. No queda claro si las costumbres son propias de los nicaraos o de los chorotegas-mangue o de los corobicíes o de los chondales, según Fernández de Oviedo, pues entre ellos se da un proceso de trasculturación. Algunas de esas características son las siguientes.

El patrón de asentamiento era característico de los agricultores, con cultivos cercanos a cargo de los hombres. En la región de Nicoya el tipo de poblado más numeroso se localizaba a lo largo de los cursos del agua permanente y en la zona alrededor del golfo de Nicoya. En la parte norte de Guanacaste, se señala que en el siglo XVI estaba bastante despoblada porque era "tierra sin agua".

En cuanto a su estructura social y en comparación con los nicaraos, la sociedad chorotega tendía a ser más democrática en el sentido de que los nobles y el cacique estaban en cierta medida subordinados a un consejo de ancianos escogidos por votos.

Los chorotegas tenían como jefe a un cacique que gobernaba sobre un territorio en el que a su vez, residían otros jefes que eran sus vasallos, los cuales estaban obligados a pagarle tributo. En los grandes poblados también se levantaban los templos atendidos por los sacerdotes encargados de realizar los sacrificios humanos y enseñar la doctrina de los dioses. Los nicaraos tenían a la cabeza del gobierno un capitán general que gobernaba junto con los 
monexicos, fuerza política que elegía al sucesor del capitán o lo mataba cuando consideraba que era inconveniente a su sistema. Las creencias religiosas de los nicaraos eran típicas de Mesoamérica y guardaban gran semejanza con las de los mexicanos: dioses de la lluvia, del agua, de los muertos, de la cacería y del sol. La organización social del cacicazgo se caracterizaba por un sistema de rangos. Una persona podía superar su condición y ascender según méritos obtenidos en la guerra o en la comunidad.

Entre los chorotegas y los nicaraos el comercio se efectuaba en los trangüez o mercados. Los instalaban debajo de las ceibas y los atendían las mujeres. Un oficial vigilaba todas las regulaciones o comodidades. El cacao se empleaba como moneda, aunque también servían el maíz y el algodón.

Tanto los nicaraos como los chorotegas tuvieron una agricultura más desarrollada que la de los otros pueblos costarricenses del sector de tradición sudamericana. La práctica de la agricultura se basaba en el cultivo del maíz que era lo más importante, ya que fue su principal alimento y la materia prima en la fabricación de su bebida embriagante: la chicha. Los frijoles, las calabazas (ayotes) y los chiles fueron cultivos muy apreciados. Los árboles frutales más conocidos fueron los zapotes, los nísperos, la papaya y el aguacate. El cacao, tostado, molido y diluido en agua, fue una bebida de principales. El tabaco también se utilizaba, principalmente, por los efectos sicotrópicos que provocaba la aspiración del humo o el jugo de las hojas al ser mascadas. Cultivaron también el algodón y la cabuya.

Los chorotegas también consumían carnes obtenidas de la caza de venados, tepezcuintes, zahínos y pavas. La gran cantidad de ríos y su contacto con el mar los proveía de una fuente inagotable de moluscos: pianguas, mejillones, chuchecas, ostras, almejas y cambutes. En la Gran Nicoya privaba una alimentación rica en proteínas, vitaminas y grasas.

Gran cantidad de árboles fueron empleados en la construcción de sus viviendas, muchos de los cuales conservan sus nombres antiguos: el guanacaste, el guayacán, el guapinol, etc.

De acuerdo con C. Meléndez (1974), el conocimiento más claro y preciso de los detalles relativos a las primeras exploraciones del Golfo de Nicoya, de las características culturales de sus primitivos pobladores y de los primeros contactos europeos y americanos en el área del golfo, se obtiene gracias a las descripciones de Fernández de Oviedo y Valdés. Aunque no tuvo cargo específico de Cronista de Indias, en la práctica sus tareas cumplieron dicha función. Con Pedrarias Dávila, Fernández de Oviedo pasa a Tierra Firme con funciones de veedor; ya por entonces empezó su interés por los relatos de los descubrimientos y de los pueblos americanos.

En 1519, Hernán Ponce de León y Juan de Castañeda, pilotos al servicio de Pedrarias Dávila, descubrieron el Golfo de Nicoya; aunque no desembarcaron, quedó conocida la importancia de aquellas tierras guanacastecas y el camino de su próxima exploración y conquista. La conquista se inició cuando Gil González Dávila recorrió a pie las costas de Nicoya y se internó en la península en los primeros meses del año 1523. Desde entonces quedaron sometidos los principales caciques de la región en forma pacífica y fueron bautizados muchos indios: "...yo me partí por tierra haciendo muchos caciques amigos y vasallos de Vuestra Majestad y tornándose todos cristianos muy de su voluntad y llegué a un cacique que se llama Nicoya el cual me dio de presente 14 mil castellanos de oro" (Meléndez 1974: 24).

Durante el recorrido González Dávila se encuentra con Andrés Niño e intenta irse con él y hacer el descubrimiento con los marineros; pero para que sus compañeros de hazaña no 
se sintieran solos, prefirió enviar a su Teniente con Andrés Niño y a otros pilotos a hacer la exploración.

Fernández de Oviedo, uno de los acompañantes de Andrés Niño, describe el recorrido que él hizo hasta el Golfo de San Lucas, Golfo de Nicaragua, Golfo de Orotiña o Golfo de Güetares que son los distintos nombres con que se conoce el mismo golfo: "Y qualquiera destos dos nombres postreros es su nombre propio. Y pintarle he como yo le vi, y no como le hallo en las cartas de nuestros cosmógrafos puesto, hasta el presente año de mil e quinientos e quarenta y ocho; e diré las principales islas que hay en esta ensenada" (Meléndez 1974: 25).

En su descripción Fernández de Oviedo menciona nombres como Puerto Herradura, Boca del Golfo de Güetares, Punta Cabo Blanco, Isla de Chira, Isla Cachoa, Isla de Chara, Provincia de Orotiña, Provincia Chorotega y más al noreste están las gentes y sierras llamados Güetares. Los güetares son mucha gente y viven encima de las sierras del Puerto de Herradura y se extienden por la costa de este golfo al poniente hasta el confín de los chorotegas. Al final del golfo hay un cacique que se llama Cipandí que tiene el nombre del río y al noreste está otro que se llama Corobicí. Al lado opuesto, en la otra costa del mismo golfo, el más cercano al río Cipandí es el Cange y más al este está otro llamado Paro.

De acuerdo con M. Quesada Pacheco, durante este período los conquistadores se contentaron con realizar viajes exploratorios por la costa y en la zona noreste de Costa Rica. Partían de Panamá y utilizaban la Península de Nicoya para sus viajes a la ciudad de León y Granada. Los centros de población que fundaron en territorio costarricense no fueron prósperos, salvo Nicoya que ya existía como centro bien establecido y poblado por los indios chorotegas. En 1524 Francisco Fernández de Córdoba fundó la villa de Bruselas en el Golfo de Nicoya, primer asentamiento español; además, en ese año, se hizo la primera repartición de indios en el país con lo cual Nicoya queda incorporada al dominio español y se convierte en una región proveedora de esclavos indios y obligada al pago de tributo en productos agrícolas a los encomenderos de León y Granada. Este hecho permitió que el indio comenzara a tener contacto con la lengua de sus vencedores.

En 1545 los indios nicoyanos estaban encomendados a Rodrigo de Contreras y su familia y, a partir de esa fecha, la colonización de Guanacaste se comenzó a difundir y a arraigar. Agüero (1962) asegura que la provincia de Guanacaste recibió más influencia de Nicaragua que de la parte central de Costa Rica. Esta influencia se acentuó más a principios del siglo XVIII. Muchos ciudadanos de Nicaragua poseían fincas en Guanacaste donde pasaban gran parte de su tiempo. Guanacaste además no dependía de la gobernación de Costa Rica, pues tuvo alcaldes mayores nombrados por la audiencia de Guatemala y luego directamente por el Rey. De modo que la conquista y colonización de ambas regiones del país se realizaron independientemente. Aun después de la Independencia el Partido de Nicoya quedó fuera de la jurisdicción política y gubernativa de Costa Rica hasta la fecha de la Anexión en 1824.

\subsection{Los chorotegas y su lengua}

En Costa Rica, se juntaron pueblos de distinta procedencia por las presiones de la guerra, de factores económicos o de cualquier otra fuerza. Este fenómeno se aprecia de manera singular en el campo de las lenguas. Las lenguas habladas en Costa Rica precolombina procedían de diferentes troncos lingüísticos. 
Según Constenla (1994), los chorotegas provienen del tronco lingüístico otomangue, de la familia otomí, habitantes del istmo de Tehuantepec, Oaxaca. La población viene del estado de Chiapas, zona en donde habitaban los chiapanecos. El grupo chiapaneco está más documentado que el chorotega; se han hecho transcripciones fonemáticas; Albornoz escribió una gramática, Barrientos elaboró un catecismo y Becerra recogió términos. Los chorotegas y los chiapanenses se llamaban a sí mismos "mangues" que probablemente significa "señores'. La población nahuatl los llamaba chorotegas. Se ubicaron en Choluteca (México), Honduras (hasta el Golfo de Fonseca), lago de Managua, Granada, Masaya (Nicaragua) y en Costa Rica en la península de Nicoya e islas del Golfo.

Con respecto a los chorotegas de Costa Rica, se cuenta con pocos términos registrados. En Nicaragua se habló esa lengua hasta el siglo XIX. Se tiene como fecha de llegada a Nicaragua el año 800 d. C. y se considera que pudieron haber entrado a Costa Rica en el año 1200 .

Los nahuas eran de la familia aztécica de la estirpe utoaztecense, estirpe cuyo lugar de origen está por el lado de Utha, Estados Unidos. Penetraron a los límites de Mesoamérica y se establecieron en el estado de Nayarit, en México, aproximadamente en el año 600 d .C , es decir que llegaron tarde a Mesoamérica, incluso se mesoamericanizaron porque originalmente los idiomas de ellos, de los utoaztecenses, no tenían las características que tienen los idiomas mesoamericanos; ya el azteca sí tiene esas características típicamente mesoamericanas porque las adquirió en contacto con los otomangues, los mayas y otros pueblos con más tiempo de estar en México. Dentro de esta familia están el azteca, que se conoce como el nahuatl clásico o azteca, el pipil y el nicarao.

Según indicios de arqueología y lingüística genética de población, se tiene que desde 3000 años a.C. podría haber estado en Costa Rica otra estirpe lingüística: la chibchense.

Los chibchas eran un grupo cultural que habitaba Bojacá y Cundinamarca. Hablaban dos idiomas. Existen muestras arqueológicas de este grupo desde el 500 d. C.

En Costa Rica, por la laguna Arenal, se hicieron estudios arqueológicos más a fondo sobre los grupos culturales chibchas, que probablemente habitaron, en algún momento, en una buena parte de nuestro país. Se considera que estuvieron ubicados primeramente al sur de Costa Rica y al oeste de Panamá, antes de llegar a Colombia.

Los grupos indígenas de la estirpe chibchense son los corobicíes (grupo ya desaparecido), los ramas (actualmente hay en Nicaragua 15 habitantes), los botos que se ubicaron hasta las faldas del volcán Poás. Se dice que sus costumbres eran diferentes, pues vivían en casas construidas en los árboles. Se da una vinculación entre los botos-ramas y botos-corobicíes, los guatusos (con 300 hablantes aproximadamente) y los huetares. Los huetares se ubicaron por el río Chomes hacia el río Parrita, de aquí al este (todo el Valle Central) y hacia el Atlántico hasta los llanos de Siquirres.

Miguel Quesada, en su libro El Español de Guanacaste, delimita la región Noroeste de Costa Rica, la cual comprende la provincia de Guanacaste, la parte noroeste de la provincia de Alajuela que colinda con Nicaragua y Guanacaste, la cuenca del río Tempisque y la sección noroeste de la provincia de Puntarenas. Para el estudio del español de esa zona propone tres grandes períodos, tomando en cuenta hechos históricos que han servido de marco para diversos cambios en el sistema lingüístico de las comunidades en cuestión. Dichas etapas son: 
- período de gestación; contacto con el sur (1519-1730)

- período de contacto con Nicaragua (1730-1900)

- período de contacto con el Valle Central (1824)

El período de gestación corresponde a la conquista de Costa Rica por los españoles, la cual se dio en dos fases: la conquista de Nicoya que precedió en cuatro décadas a la del Valle Central y coincidió con el período de las grandes aventuras en América del Sur y la segunda fase que se inaugura con la expedición de Juan de Cavallón al Valle Central. En esta etapa se destaca la fundación de Aranjuez por Perafán de Rivera en 1568; luego reubicada en su sitio actual con el nombre de Ciudad del Espíritu Santo de Esparza.

A partir de 1564 Nicoya abrió comercio con Panamá. Se exportaba ganado caballar, mular y sebo, además se comerciaba con bizcocho o totoposte. Este contacto con Panamá y Perú va a ayudar a conformar un tipo de español en el Pacífico norte, divergente del español del Valle Central. De igual manera el español de Guanacaste se impregna con palabras de origen sureño.

La segunda etapa se inicia hacia 1730 cuando decae el comercio con Panamá y, en su lugar, se orienta hacia los mercados de Guatemala y Nicaragua. Estos factores marcan una nueva etapa en el desarrollo del español del noroeste, pues ayudaron a fortalecer los lazos lingüísticos entre la sección norte de la actual provincia de Guanacaste con Nicaragua. Con la decadencia de Granada a mediados del siglo XVII, se produce un éxodo hacia el sur. En 1720 se fundó la villa de la Purísima Concepción de Nicaragua de Rivas. Los habitantes de Rivas continuaron sus desplazamientos hacia el sur donde establecieron grandes haciendas ganaderas.

La tercera etapa corresponde al período de contacto con el Valle Central. Después de la Independencia y de la Anexión de Guanacaste a Costa Rica, se dio un proceso de interrelación entre ambos: el comercio de ganado comenzó a virar hacia el Valle Central, además, hacia finales del siglo XIX y principios del XX, diversos grupos colonizadores del valle se asentaron en las tierras altas o bien hacia las costas de la provincia de Guanacaste. Los nuevos habitantes no sólo llevaron al Guanacaste un nuevo tipo de vida, desconocido en la provincia (sistema de parcelas, cultivo del café), sino una variedad dialectal diferente de la guanacasteca.

\section{Topónimos de origen indígena: sus lenguas}

Siguiendo el modelo de análisis propuesto en Toponimia de la provincia de Cartago (Garita 1995: 26), el corpus correspondiente a nombres procedentes de nombres indígenas se ha organizado de la forma siguiente.

Los nombres de origen indígena pueden proceder de nombres propios o de nombres comunes. En el primer caso, se trata de nombres topónimos que corresponden al sustrato, es decir, nombres creados por la etnia que existió en la provincia antes de la llegada de los españoles. Esto se corrobora en las descripciones hechas por los españoles Alonso de Castañeda, Gil González Dávila y Fernández de Oviedo, en su recorrido por el área de Guanacaste. En el segundo caso, topóriimos procedentes de nombres comunes, se trata de nombres indígenas que entraron como préstamo al español y pasaron a formar parte del léxico hispánico.

Del primer grupo tenemos los siguientes: 


\subsection{Nombres procedentes de nombres propios}

$\begin{array}{llll}\text { TOPÓNIMO } & \text { LENGUA } & \text { CARACTERÍSTICA } & \text { MAPA BÁSICO } \\ & & & \\ \text { Bagaces } & \text { Corobicí } & \text { Poblado } & \text { Monteverde } \\ \text { Bagaces } & \text { Corobicí } & \text { Río } & \text { Cañas } \\ \text { Bagaces } & \text { Corobicí } & \text { Río } & \text { Monteverde } \\ \text { Canjel } & \text { Chorotega } & \text { Poblado } & \text { Venado } \\ \text { Canjel } & \text { Chorotega } & \text { Quebrada } & \text { Venado } \\ \text { Canjelito } & \text { Chorotega } & \text { Poblado } & \text { Berrugate } \\ \text { Canjelito } & \text { Chorotega } & \text { Estero } & \text { Berrugate } \\ \text { Canjelito } & \text { Chorotega } & \text { Río } & \text { Berrugate } \\ \text { Corobicí } & \text { Corobicí } & \text { Hacienda } & \text { Cañas } \\ \text { Corobicí } & \text { Corobicí } & \text { Poblado } & \text { Cañas } \\ \text { Curime } & \text { Chorotega } & \text { Poblado } & \text { Matambú } \\ \text { Curime } & \text { Chorotega } & \text { Poblado } & \text { Matambú } \\ \text { Curime } & \text { Chorotega } & \text { Quebrada } & \text { Matambú } \\ \text { Curime } & \text { Chorotega } & \text { Río } & \text { Matambú } \\ \text { Diriá } & \text { Chorotega } & \text { Poblado } & \text { Diriá } \\ \text { Nacahome } & \text { Chorotega } & \text { Poblado } & \text { Matambú } \\ \text { Nambí } & \text { Chorotega } & \text { Poblado } & \text { Diriá } \\ \text { Nicoya } & \text { Chorotega } & \text { Poblado } & \text { Matambú } \\ \text { Nosara } & \text { Chorotega } & \text { Poblado } & \text { Garza } \\ \text { Nosara } & \text { Chorotega } & \text { Punta } & \text { Garza } \\ \text { Nosarita } & \text { Chorotega } & \text { Poblado } & \text { Matambú } \\ \text { Orosí } & \text { Corobicí } & \text { Volcán, Quebrada, Río } & \text { Cacao, Orosí } \\ \text { Orosilito } & \text { Corobicí } & \text { Cerro } & \text { Cacao } \\ \text { Taboré } & \text { Chorotega } & \text { Cerro } & \text { Carrillo Norte } \\ & & & \end{array}$

La mayoría de estos nombres corresponden a nombres de caciques que, a su vez, le dieron el nombre a los grupos bajo su dominio. Tal es el caso de Abangares, Corobicí, Curime, Canjel, Diriá y Nambí. Este último, según Fernández de Oviedo, procedía de un nombre común y su significado era "perro".

El nombre Canjel se relaciona con Canjén que, según Gagini, era el nombre de un poderoso cacique de aquella comarca, el cual le regaló gran cantidad de oro a Gil González Dávila en 1522.

Diriá, según Gagini, era un cacique de aquel lugar y su nombre en Chorotega significaba "lomas". Quirós (1986) analiza la etimología de la palabra, cuya traducción sería más o menos 'montañeros' o 'montañeses'.

Corobicí, de acuerdo con Agüero (1996), es el nombre del indio perteneciente a una tribu de Costa Rica ya desaparecida; estuvo asentada en la región oriental de los ríos Tempisque, Bebedero y Tenorio, desde la ribera del Golfo de Nicoya hasta Tilarán. También se llamó "Corobicí" a la lengua de estos indios. De acuerdo con Constenla, Corobicí es el nombre de 
un grupo indígena de la estirpe chibchense de la cual sólo quedó la palabra que le dio nombre al río Corobicí. Es característica del chibchense la terminación -ci para hidrónimos, "si" 'agua, río'.

Para Quesada Pacheco (Entrevista personal: 1997) los nombres Nandayure, Nimboyores, Nosara, Nicoya y Nacahome son probablemente de origen chorotega y el nombre Bagaces de origen corobicí. No obstante, la investigación filogenética que él lleva a cabo aún no se ha concluido.

En el caso de Abangares, no se ha establecido la lengua de procedencia; los informantes Ofelia Gamboa Solórzano y Romain Vega Cortés coinciden en que Abangares es el nombre del cacique Abancari, pero Ofelia manifiesta que la palabra abancari significa 'señor de los esteros' y Romain Vega dice que abancarí significa 'fuerza de las aguas' porque ahí, en la Sierra de Abangares, hay muchos nacientes.

\subsection{Topónimos procedentes de nombres comunes indígenas}

Son nombres procedentes del vocabulario común que pasaron a integrarse al castellano como nombres comunes y luego se convirtieron en nombres topónimos. Este grupo, a su vez, lo dividiremos en dos subgrupos: Términos foráneos: se refieren a nombres indígenas de otras lenguas de América, traídos por los españoles a estos lugares y, Términos autóctonos: nombres del vocabulario común que luego se convirtieron en topónimos.

\subsubsection{Términos foráneos}

TOPÓNIMO

Achiotal

Achiotal

Achiotal

Acoyapa

Aguacata

Aguacate

Aguacate

Aguacate

Aguacate

Aguacate

Aguacate

Aguacatico

Aguacate

Aguacate

Ayote

Ayote

Ayote

Ayotes

Ayotes

\section{LENGUA}

Nahua

Nahua

Nahua

Nahua

Nahua

Nahua

Nahua

Nahua

Nahua

Nahua

Nahua

Nahua

Nahua

Nahua

Nahua

Nahua

Nahua

Nahua

Nahua
CARACTERÍSTICA

Cerro

Estero

Quebrada

Poblado

Quebrada

Finca

Quebrada

Quebrada

Quebrada

Quebrada

Río

Quebrada

Poblado

Poblado

Loma

Quebrada

Quebrada

Estero

Poblado
MAPA BÁSICO

Matapalo

Tempisque

Diriá

Matambú

Cerro Brujo

Monteverde

Curubandé

Diriá

Monteverde

Tierras Morenas

Arenal

Arenal

Arenal

Diriá

Talolinga

Bahía Salinas

Cañas

Abangares

Tilarán 
TOPÓNIMO

Bejuco

Bejuco

Bejuco

Bejuco

Bejuco

Bejuco

Bejuco

Bejuquito

Bijagua

Bijagua

Bijagual

Biscayal

Biscoyol

Biscoyol

Biscoyol

Biscoyol

Biscoyol

Biscoyol

Biscoyol

Cabuyo

Cacao

Cacao

Cacao

Cacao

Cacao

Cacao

Cacao

Cacao

Cacao

Cacao

Cacao

Cacao

Cacao

Cacao

Cacao

Cacao

Cacao

Cacao

Cacao

Cacao

Cacao

Cacao
LENGUA

Tahíno

Tahíno

Tahíno

Tahíno

Tahíno

Tahíno

Tahíno

Tahíno

Tahíno

Tahíno

Tahíno

Nahua

Nahua

Nahua

Nahua

Nahua

Nahua

Nahua

Nahua

Tahíno

Nahua

Nahua

Nahua

Nahua

Nahua

Nahua

Nahua

Nahua

Nahua

Nahua

Nahua

Nahua

Nahua

Nahua

Nahua

Nahua

Nahua

Nahua

Nahua

Nahua

Nahua

Nahua
CARACTERÍSTICA

Estero

Laguna

Playa

Poblado

Poblado

Quebrada

Río

Quebrada

Cerro

Poblado

Poblado

Quebrada

Cerro

Poblado

Quebrada

Quebrada

Quebrada

Quebrada

Quebrada

Finca

Estero

Estero

Finca

Laguna

Poblado

Poblado

Poblado

Quebrada

Quebrada

Río

Quebrada

Quebrada

Quebrada

Quebrada

Quebrada

Quebrada

Quebrada

Quebrada

Quebrada

Quebrada

Quebrada

Quebrada
MAPA BÁSICO

Puerto Coyote

Cerro Azul

Cerro Azul

Ahogados

Cerro Azul

Talolinga

Cerro Azul

Monteverde

Cerro Brujo

Cerro Brujo

Cerro Brujo

Cerro Brujo

Talolinga

Talolinga

Diriá

Matambú

Talolinga

Tempisque

Villarreal

Tierras Morenas

Matapalo

Tempisque

Talolinga

Tierras Morenas

Bahía Salinas

Diriá

Matambú

Matambú

Matambú

Matambú

Ahogados

Bahía Salinas

Cerro Azul

Cerro Azul

Cerro Brujo

Cerro Brujo

Diriá

Diriá

Garza

Juntas

Marbella

Matambú 


\section{TOPÓNIMO}

Cacao

Cacao

Cacao

Cacao

Cacao

Cacique

Caimital

Caimital

Caimital

Caimitalito

Caimito

Caimito

Caimito

Capulin

Capulín

Capulín

Capulín

Capulín

Capulinal

Caraña

Caucela

Ceiba (La)

Ceiba

Ceiba

Ceiba

Ceiba

Ceiba

Ceiba

Ceiba

Ceiba

Ceiba

Ceiba

Ceiba

Ceiba

Ceiba

Ceiba

Ceibita (La)

Ceiba Mocha

Ceiba Mocha

Chagüite

Chinampas

Chinampas
LENGUA

Nahua

Nahua

Nahua

Nahua

Nahua

Insular

Arauaco

Arauaco

Arauaco

Arauaco

Arauaco

Arauaco

Arauaco

Azteca

Azteca

Azteca

Azteca

Azteca

Azteca

Dial. indíg. venezol.

Azteca

Tahíno

Tahíno

Tahíno

Tahíno

Tahíno

Tahíno

Tahíno

Tahíno

Tahíno

Tahíno

Tahíno

Tahíno

Tahíno

Tahíno

Tahíno

Tahíno

Tahíno

Tahíno

Azteca

Azteca

Azteca
CARACTERÍSTICA

Quebrada

Quebrada

Quebrada

Río

Río

Cerros

Poblado

Quebrada

Río

Poblado

Poblado

Poblado

Quebrada

Cerro

Cerro

Finca

Lomas

Poblado

Loma

Quebrada

Loma

Cerro

Cerro

Cerro

Finca

Finca

Hacienda

Poblado

Quebrada

Quebrada

Quebrada

Quebrada

Quebrada

Quebrada

Quebrada

Quebrada

Finca

Poblado

Quebrada

Finca

Cerro

Poblado
MAPA BÁSICO

Matambú

Murciélago

Tierras Morenas

Cañas

Matapalo

Diriá

Matambú

Matambú

Matambú

Matambú

Matambú

Diriá

Diriá

Garza

Matapalo

Monteverde

Diriá

Monteverde

Orosí

Monteverde

Cerro Brujo

Matapalo

Carrillo Norte

Garza

Belén

Talolinga

Matambú

Matambú

Abangares

Belén

Cañas

Cerro Brujo

Diriá

Matapalo

Matapalo

Tierras Morenas

Chapernal

Diriá

Diriá

Matapalo

Cerro Azul

Cerro Azul 


\section{TOPÓNIMO}

Chincaca

Chilamate

Chilamate

Chilamo

Chocoaca

Chocoyas

Chonta

Choluteca

Copal

Copal

Copal

Copey

Coyol

Coyol

Coyol

Coyol

Coyol

Coyol

Coyol

Coyolar

Coyolar

Coyolar

Coyolar

Coyolar

Coyolar

Coyolar

Coyolar

Coyolar

Coyolar

Coyolar

Coyolar

Coyolar

Coyolarcitos

Coyolera

Coyoles

Coyolito

Coyolito

Coyolito

Coyolito

Coyote

Coyote

Coyote

\section{LENGUA}

Nahua

Azteca

Azteca

Azteca

Nahua

Pipil

Quechua

Nahua

Azteca

Azteca

Azteca

Haitiano

Azteca

Azteca

Azteca

Azteca

Azteca

Azteca

Azteca

Azteca

Azteca

Azteca

Azteca

Azteca

Azteca

Azteca

Azteca

Azteca

Azteca

Azteca

Azteca

Azteca

Azteca

Azteca

Azteca

Azteca

Azteca

Azteca

Azteca

Nahua

Nahua

Nahua
CARACTERÍSTICA

Quebrada

Quebrada

Quebrada

Estero

Finca

Islote

Quebrada

Finca

Playa

Poblado

Río

Quebrada

Finca

Finca

Poblado

Laguna

Quebrada

Quebrada

Quebrada

Cerro

Cerro

Cerro

Cerros

Finca

Hacienda

Hacienda

Poblado

Quebrada

Quebrada

Quebrada

Quebrada

Quebrada

Quebrada

Playa

Cerro

Alto

Poblado

Poblado

Río

Cerro

Cerro

Estero
MAPA BÁSICO

Abangares
Talolinga
Villarreal
Berrugate
Diriá
Matapalo
Puerto Coyote
Tierras Morenas
Bahía Salinas
Talolinga
Bahía Salinas
Tierras Morenas
Tierras Morenas

Cañas

Carrillo Norte

Bahía Salinas

Abangares

Diriá

Matapalo

Belén

Diriá

Matambú

Talolinga

Belén

Ahogados

Tierras Morenas

Diriá

Diriá

Diriá

Diriá

Matambú

Matapalo

Monteverde

Bahía Salinas

Cerro Brujo

Carrillo Norte

Belén

Chapernal

Belén

Río Ario

Venado

Puerto Coyote 


\section{TOPÓNIMO}

Coyote

Coyote

Coyote

Coyote

Coyotera

Coyotes (Los)

Coyotes

Cuajiniquil

Cuajiniquil

Cuajiniquil

Cuajiniquil

Cuajiniquil

Cuajiniquil

Cuajiniquil

Cuajiniquil

Cuajiniquil

Cuajiniquil

Cuipilapa

Cusuca

Cusuca

Eskameca

Espavel

Espavel

Espavel

Espavel

Espavel

Espavelar

Espavelar

Espavelar

Espavelar

Espavelar

Espavelar

Espavelosa

Guacalito

Guacamaya

Guacamayo

Guachipelín

Guachipelín

Guachipelín

Guachipelín

Guachipelín

Guachipelín
LENGUA

Nahua

Nahua

Nahua

Nahua

Nahua

Nahua

Nahua

Nahua

Nahua

Nahua

Nahua

Nahua

Nahua

Nahua

Nahua

Nahua

Nahua

Azteca

Nahua

Nahua

Nahua

Haitiano

Haitiano

Haitiano

Haitiano

Haitiano

Haitiano

Haitiano

Haitiano

Haitiano

Haitiano

Haitiano

Haitiano

Nahua

Azteca

Haitiano

Nahua

Nahua

Nahua

Nahua

Nahua

Nahua
CARACTERÍSTICA

Lomas

Playa

Punta

Río

Quebrada

Cerro

Finca

Fila

Bahía

Playa

Poblado

Poblado

Poblado

Quebrada

Quebrada

Río

Río

Poblado

Quebrada

Laguna

Cerro

Quebrada

Quebrada

Quebrada

Quebrada

Quebrada

Finca

Finca

Finca

Quebrada

Quebrada

Río

Laguna

Finca

Finca

Cerros

Cerro

Cerro

Cerro

Fila

Fila

Finca
MAPA BÁSICO

Diriá

Puerto Coyote

Diriá

Puerto Coyote

Curubandé

Villarreal

Curubandé

Cerro Brujo

Murciélago

Marbella

Cerro Brujo

Cerro Brujo

Murciélago

Cerro Brujo

Matapalo

Cerro Brujo

Murciélago

Miravalles

Matapalo

Tierras Morenas

Cañas

Bahía Salinas

Belén

Carrillo Norte

Talolinga

Villarreal

Diriá

Matambú

Diriá

Cerro Brujo

Talolinga

Murciélago

Tierras Morenas

Tierras Morenas

Punta Gorda

Talolinga

Matapalo

Belén

Santa Elena

Belén

Matapalo

Tierras Morenas 


\section{TOPÓNIMO}

Guachipelín

Guachipelín

Guachipelín Rancho

Guachipelines

Guácimo

Guácimo

Guácimo

Guácimo

Guácimo

Guaitil

Guaitil

Guaitil

Guaitil

Guaitil

Guaitilar

Guaitilar

Guanacaste

Guanacaste

Guanacaste

Guanacastillo

Guanacaste Mocho

Guape

Guape

Guape

Guape

Guape

Guapes

Guapes

Guapes

Guapes

Guapes Boca

Guapinol

Guapinol

Guapinol

Guapinol

Guapinol

Guapote

Guapote

Guapote

Guastomatal

Guastomatal

Guastomatal

\section{LENGUA}

Nahua

Nahua

Nahua

Nahua

Haitiano

Haitiano

Haitiano

Haitiano

Haitiano

Nahua

Nahua

Nahua

Nahua

Nahua

Nahua

Nahua

Nahua

Azteca

Azteca

Azteca

Azteca

Azteca

Azteca

Azteca

Azteca

Azteca

Azteca

Azteca

Azteca

Azteca

Azteca

Nahua

Nahua

Nahua

Nahua

Nahua

Nahua/Quiché

Nahua/Quiché

Nahua

Nahua

Nahua

Nahua
CARACTERÍSTICA

Hacienda

Loma

Poblado

Punta

Finca

Finca

Laguna

Quebrada

Quebrada

Cerro

Poblado

Poblado

Quebrada

Quebrada

Cerro

Lomas

Cordillera

Quebrada

Quebrada

Quebrada

Finca

Quebrada

Quebrada

Quebrada

Quebrada

Quebrada

Lomas

Quebrada

Quebrada

Quebrada

Quebrada

Poblado

Poblado

Poblado

Quebrada

Quebrada

Hacienda

Poblado

Quebrada

Cerro

Fila

Poblado

\section{MAPA BÁSICO}

Curubandé

Diriá

Diriá

Matapalo

Talolinga

Tierras Morenas

Villarreal

Murciélago

Talolinga

Belén

Diriá

Matambú

Diriá

Tilarán

Juntas

Juntas

Curubandé

Cerro Brujo

Garza

Ahogados

Belén

Arenal

Arenal

Garza

Talolinga

Venado

Abangares

Belén

Cerro Azul

Matapalo

Cerro Brujo

Abangares

Bahía Salinas

Cerro Azul

Bahía Salinas

Cerro

Ahogados

Diriá

Ahogados

Cerro Brujo

Matambú

Cerro Brujo 


\section{TOPÓNIMO}

Guastomatal

Guastomatal

Guastomatal

Guastomatal

Guastomatal

Guastomatal

Guastomatal

Guastomate

Guastomate

Guastomate

Guatusa

Guatusa

Guayabal

Guayabal

Guayabal

Guayabalosa

Guayabo

Guayabo

Guayabo

Guayabo

Guayabo

Guayabo

Guayabo

Guayacán

Guies

Henequenes

Huacal

Huacalito

Huacalito

Huacalito

Huacas

Huacas

Huacas

Huacas

Huacas

Huacas

Huacas

Huacas (Las)

Huacas

Huacas

Huaquitas

Huaquitos (Los)
LENGUA

Nahua

Nahua

Nahua

Nahua

Nahua

Nahua

Nahua

Nahua

Nahua

Nahua

Nahua

Nahua

Arauaco Insular

Arauaco Insular

Arauaco Insular

Arauaco Insular

Arauaco Insular

Arauaco Insular

Arauaco Insular

Arauaco Insular

Arauaco Insular

Arauaco Insular

Arauaco Insular

Tahíno

Nahua

Maya

Nahua

Nahua

Nahua

Nahua

Quechua

Quechua

Quechua

Quechua

Quechua

Quechua

Quechua

Quechua

Quechua

Quechua

Quechua

Quechua
CARACTERÍSTICA

Poblado

Poblado

Quebrada

Quebrada

Quebrada

Quebrada

Quebrada

Fila

Quebrada

Quebrada

Quebrada

Quebrada

Laguna

Poblado

Quebrada

Fila

Finca

Poblado

Poblado

Quebrada

Quebrada

Quebrada

Río

Poblado

Quebrada

Estero

Poblado

Cerro

Finca

Finca

Cerro

Cerro

Cerro

Loma

Finca

Finca

Finca

Poblado

Poblado

Poblado

Poblado

Lomas
MAPA BÁSICO

Matambú

Matambú

Cerro Brujo

Cerro Brujo

Matambú

Matambú

Matambú

Cerro Azul

Belén

Villarreal

Cerro Brujo

Venado

Bahía Salinas

Miravalles

Monteverde

Matapalo

Cerro Azul

Miravalles

Talolinga

Belén

Tempisque

Tilarán

Miravalles

Abangares

Matambú

Tempisque

Tierras Morenas

Tempisque

Murciélago

Villarreal

Cañas

Diriá

Matambú

Tempisque

Abangares

Diriá

Monteverde

Abangares

Matambú

Matapalo

Carrillo Norte

Belén 


\section{TOPÓNIMO}

\section{LENGUA}

CARACTERÍSTICA

MAPA BÁSICO

\begin{tabular}{|c|c|c|c|}
\hline Icacal & Tahíno & Estero & Villarreal \\
\hline Icacal & Tahíno & Poblado & Villarreal \\
\hline Icacal & Tahíno & Río & Villarreal \\
\hline Iguanita & Arauaco & Finca & Carrillo Norte \\
\hline Iguanita & Arauaco & Poblado & Matambú \\
\hline Jabilla (Millal) & Nahua & Cerro & Cerro Azul \\
\hline Jabilla & Nahua & Cerro & Cañas \\
\hline Jabilla & Nahua & Cerro & Puerto Coyote \\
\hline Jabillas & Nahua & Cerro & Cerro Azul \\
\hline Jabilla Abajo & Nahua & Poblado & Cañas \\
\hline Jabilla Arriba & Nahua & Poblado & Cañas \\
\hline Jabilla & Nahua & Estero & Puerto Coyote \\
\hline Jabilla & Nahua & Finca & Puerto Coyote \\
\hline Jabilla & Nahua & Quebrada & Puerto Coyote \\
\hline Jabilla & Nahua & Río & Cañas \\
\hline Jabillo & Nahua & Quebrada & Talolinga \\
\hline Jabillo & Nahua & Río & Venado \\
\hline Jabito & Nahua & Quebrada & Cerro Azul \\
\hline Jabillos & Nahua & Poblado & Venado \\
\hline Jicarito & Azteca & Estero & Abangares \\
\hline Jicarito & Azteca & Quebrada & Matapalo \\
\hline Jícaro & Azteca & Playa & Carrillo Norte \\
\hline Jícaro & Azteca & Quebrada & Garza \\
\hline Jícaro & Azteca & Quebrada & Matambú \\
\hline Jícaro & Nahua & Bahía & Murciélago \\
\hline Jicote & Nahua & Bahía & Carrillo Norte \\
\hline Jicote & Nahua & Loma & Marbella \\
\hline Jicote & Nahua & Loma & Monteverde \\
\hline Jicote & Nahua & Lomas & Tempisque \\
\hline Jicote $(\mathrm{El})$ & Nahua & Bahía & Murciélago \\
\hline Jicote & Nahua & Laguna & Tempisque \\
\hline Jobitos & Tahíno & Laguna & Tempisque \\
\hline Jobito & Tahíno & Loma & Carrillo Norte \\
\hline Jobo (El) & Tahíno & Estero & Tempisque \\
\hline Jobo (El) & Tahíno & Hacienda & Ahogados \\
\hline Jobo (El) & Tahíno & Poblado & Cerro Azul \\
\hline Jobo & Tahíno & Poblado & Belén \\
\hline Jobo & Tahíno & Poblado & Bahía Salinas \\
\hline Jobo & Tahíno & Poblado & Cerro Brujo \\
\hline Jobo (El) & Tahíno & Quebrada & Abangares \\
\hline Jobo (El) & Tahíno & Quebrada & Ahogados \\
\hline Jobo & Tahíno & Quebrada & Belén \\
\hline
\end{tabular}




\section{TOPÓNIMO}

Jobo

Jobo

Jobos (Los)

Jobos

Jobos

Jobos

Jocote

Jocote

Jocotes

Jocotillo

Jobitos

Manglar

Mica

Mica

Michigüiste

Michigüiste

Michigüiste

Mico (El)

Micos

Micos

Mozotal

Mozotal

Nacascolo

Nambira

Nance

Nancital

Nancital

Nancital

Nancital

Nancital

Nancital

Nancital

Nancite

Ocotal

Ocotal

Ojochada

Ojochal

Ojochal

Ojochal

Ojochal

Ojochal

Ojochal
LENGUA

Haitiano

Haitiano

Tahíno

Tahíno

Tahíno

Tahíno

Nahua

Nahua

Nahua

Nahua

Nahua

Arauaco

Cumanagota

Cumanagota

Nahua

Nahua

Nahua

Cumanagota

Cumanagota

Cumanagota

Nahua

Nahua

Nahua

Azteca

Azteca

Azteca

Azteca

Azteca

Azteca

Azteca

Azteca

Azteca

Azteca

Azteca

Azteca

Nahua

Nahua

Nahua

Nahua

Nahua

Nahua

Nahua
CARACTERÍSTICA

Quebrada

Quebrada

Finca

Loma

Poblado

Quebrada

Cerro

Poblado

Finca

Cerro

Finca

Poblado

Laguna

Quebrada

Laguna

Estero

Estero

Quebrada

Estero

Río

Cerro

Poblado

Poblado

Fila

Loma

Cerro

Cerro

Fila

Lomas

Poblado

Poblado

Poblado

Cerro

Cerros

Bahía

Laguna

Finca

Finca

Llanos

Poblado

Quebrada

Quebrada
MAPA BÁSICO

Cerro Azul

Tierras Morenas

Villarreal

Diriá

Diriá

Villarreal

Tempisque

Belén

Diriá

Belén

Curubandé

Miravalles

Tierras Morenas

Tilarán

Cañas

Abangares

Tempisque

Carrillo Norte

Tempisque

Garza

Carrillo Norte

Miravalles

Carrillo

Tempisque

Ahogados

Garza

Garza

Belén

Juntas

Belén

Carrillo

Juntas

Marbella

Belén

Carrillo

Monteverde

Diriá

Belén

Santa Elena

Belén

Belén

Carrillo Norte 
TOPÓNIMO

Ojochal

Ojochal

Ojoche (El)

Ojoche

Ojoches

Ojochillal

Ojochillal

Pajuila

Papaturro

Papaturro

Papaturro

Papaturro

Piches

Piches

Piches (Los)

Piches

Piches

Pijije

Pijije

Pijije

Pijije

Pita (La)

Pita (La)

Pita

Pita

Pita

Pita

Pita Rayada

Pita Rayada

Pita Rayada

Pitahaya

Pitahaya

Pitahaya

Pitahaya

Pitahaya

Pital

Pital

Pital

Pital

Pital

Pital

Pital
LENGUA

Nahua

Nahua

Nahua

Nahua

Nahua

Nahua

Nahua

Quechua

Nahua

Nahua

Nahua

Nahua

Azteca

Azteca

Azteca

Azteca

Azteca

Nahua

Nahua

Nahua

Nahua

Arauaco

Arauaco

Arauaco

Arauaco

Arauaco

Arauaco

Arauaco

Arauaco

Arauaco

Arauaco

Arauaco

Arauaco

Arauaco

Arauaco

Arauaco

Arauaco

Arauaco

Arauaco

Arauaco

Arauaco

Arauaco
CARACTERÍSTICA

Quebrada

Quebrada

Poblado

Quebrada

Quebrada

Cerro

Quebrada

Quebrada

Playas

Quebrada

Río

Río

Estero

Poblado

Quebrada

Quebrada

Quebrada

Finca

Hacienda

Río

Poblado

Alto

Quebrada

Quebrada

Quebrada

Quebrada

Quebrada

Cerro

Poblado

Quebrada

Playa

Poblado

Punta

Quebrada

Islotes

Finca

Finca

Poblado

Quebrada

Quebrada

Quebrada

Quebrada
MAPA BÁSICO

Diriá

Garza

Tempisque

Carrillo Norte

Tempisque

Matambú

Matambú

Marbella

Bahía Salinas

Cañas

Bahía Salinas

Belén

Tempisque

Monteverde

Diriá

Abangares

Monteverde

Monteverde

Monteverde

Monteverde

Monteverde

Carrillo Norte

Garza

Carrillo Norte

Cerro Azul

Matambú

Río Ario

Matambú

Matambú

Cerro Brujo

Marbella

Marbella

Marbella

Marbella

Matapalo

Diriá

Tierras Morenas

Curubandé

Cerro Azul

Curubandé

Curubandé

Diriá 


\section{TOPÓNIMO}

Pital

Pital

Pital

Pital

Pital

Pital

Pital

Pizote

Pochota

Pochotada

Pochotada

Pochotada

Pochote

Pochote

Pochote

Pochote

Pochote

Pochote

Pochotes

Pochotes

Pochotes

Pochotes

Pochotes

Pochotes

Pocosol

Poroporo

Quelites

Soncoyo

Soncuán

Talolinga

Talolinguita

Tapezco

Tapezco

Tempatal

Tempate

Tempisque

Tempisque

Tempisque

Tempisque

Tizate

Tucera

Tule
LENGUA

Arauaco

Arauaco

Arauaco

Arauaco

Arauaco

Arauaco

Arauaco

Nahua

Nahua

Nahua

Nahua

Nahua

Nahua

Nahua

Nahua

Nahua

Nahua

Nahua

Nahua

Nahua

Nahua

Nahua

Nahua

Nahua

Nahua

Quichua

Nahua

Nahua

Nahua

Nahua

Nahua

Nahua

Nahua

Azteca

Azteca

Nahua

Nahua

Nahua

Nahua

Nahua

Nahua

Nahua
CARACTERÍSTICA

Quebrada

Quebrada

Quebrada

Quebrada

Quebrada

Quebrada

Quebrada

Quebrada

Finca

Lomas

Finca

Poblado

Bahía

Estero

Laguna

Loma

Quebrada

Quebrada

Cerro

Estero

Playa

Playa

Quebrada

Quebrada

Río

Poblado

Quebrada

Río

Quebrada

Poblado

Poblado

Poblado

Quebrada

Poblado

Poblado

Cerro

Finca

Hacienda

Río

Río

Quebrada

Quebrada
MAPA BÁSICO

Monteverde

Talolinga

Talolinga

Tempisque

Tierras Morenas

Venado

Villarreal

Matambú

Cañas

Tempisque

Belén

Tempisque

Carrillo Norte

Matambú

Abangares

Diriá

Diriá

Talolinga

Cerro Azul

Talolinga

Bahía Salinas

Villarreal

Monteverde

Villarreal

Bahía Salinas

Belén

Berrugate

Diriá

Monteverde

Talolinga

Talolinga

Bahía Salinas

Curubandé

Bahía Salinas

Belén

Venado

Diriá

Diriá

Tierras Morenas

Curubandé

Matapalo

Belén 


\section{TOPÓNIMO}

\section{Viscoyola}

Yuca

Yucal

Zacate

Zacate

Zacate

Zacate

Zacatales

Zacate

Zacateca

Zapotal

Zapotal

Zapotal

Zapotal

Zapotal

Zapotal

Zapote

Zapote

Zapote

Zapote (Mico)

Zapote (Mico)

Zapote

Zapote

Zapote

Zapote

Zapote

Zapote

Zapote

Zapote

Zapote

Zapote

Zapote

Zapote

Zapote

Zapote

Zapote

Zapote

Zapote

Zapotillal

Zapotillal

Zapotillo

Zompopa

\section{LENGUA}

Nahua

Arauaco

Arauaco

Nahua

Nahua

Nahua

Nahua

Nahua

Nahua

Nahua

Nahua

Nahua

Nahua

Nahua

Nahua

Nahua

Nahua

Nahua

Nahua

Nahua

Nahua

Nahua

Nahua

Nahua

Nahua

Nahua

Nahua

Nahua

Nahua

Nahua

Nahua

Nahua

Nahua

Nahua

Nahua

Nahua

Nahua

Nahua

Nahua

Nahua

Nahua

Nahua

\section{CARACTERÍSTICA}

Quebrada

Quebrada

Loma

Cerro

Cerro

Loma

Punta

Quebrada

Quebrada

Quebrada

Cerros

Estero

Finca

Punta

Quebrada

Río

Cerro

Cerro

Fila

Quebrada

Quebrada

Quebrada

Quebrada

Quebrada

Quebrada

Quebrada

Quebrada

Quebrada

Quebrada

Quebrada

Quebrada

Quebrada

Río

Río

Río

Río

Río

Río

Bahía

Playa

Quebrada

Cerro

\section{MAPA BÁSICO}

Curubandé

Villarreal

Belén

Belén

Belén

Talolinga

Bahía Salinas

Matambú

Diriá

Cerro Azul

Abangares

Abangares

Punta Gorda

Punta Gorda

Matapalo

Cerro Azul

Abangares

Talolinga

Venado

Cerro Brujo

Cerro Brujo

Abangares

Belén

Cacao

Cerro Azul

Cerro Brujo

Cerro Brujo

Diriá

Marbella

Talolinga

Venado

Villarreal

Cerro Brujo

Diriá

Juntas

Matapalo

Matapalo

Talolinga

Carrillo Norte

Matapalo

Matambú

Matambú 


\section{TOPÓNIMO}

Zompopa

Zompopero

Zonchiche

Zoncho (El)

Zopilota

Zopilota

Zopilote
LENGUA

Nahua

Nahua

Azteca

Azteca

Nahua

Nahua

Nahua
CARACTERÍSTICA

Quebrada

Quebrada

Cerro

Alto

Quebrada

Río

Quebrada

\section{MAPA BÁSICO}

Matambú

Diriá

Villarreal

Tilarán

Matambú

Monteverde

Curubandé

\subsubsection{Términos autóctonos}

\section{TOPÓNIMO}

Jorcal

Jorcal

Jorco

Mojal

Mojal

Mojal

Mojal

Mojal

Nandamojo

Nandayure

Nimboyores

Nimboyores

Orosí

Orosí

Orosí

Orosí

Orosilito

Purruja

Tiquirusas

Turún

Turruja

Turrujal
LENGUA

Huetar

Huetar

Huetar

Chorotega

Chorotega

Chorotega

Chorotega

Chorotega

Chorotega

Chorotega

Chorotega

Chorotega

Corobicí

Corobicí

Corobicí

Corobicí

Corobicí

Huetar

Huetar

Huetar

Huetar

Huetar

\section{CARACTERÍSTICA}

Ojo de Agua

Quebrada

Quebrada

Quebrada

Quebrada

Finca

Finca

Hacienda

Río

Río, Cerro

Río

Finca

Volcán

Río

Río

Quebrada

Cerro

Finca

Quebrada

Cerro

Estero

Estero

\section{MAPA BÁSICO}

Monteverde

Juntas

Monteverde

Belén

Villarreal

Matapalo

Villarreal

Belén

Villarreal

Berrugate

Belén

Diriá

Cacao

Orosi

Orosi

Orosi

Cacao

Belén

Abangares

Belén

Tempisque

Tempisque

\subsection{Topónimos de origen incierto o no determinado aún}

En este apartado se incluye un grupo de topónimos que parecen de origen indígena. En algunos casos los diccionarios los incluyen como "de América", "de Centroamérica" y dan un significado; en otros se dan etimologías y significados, pero con pruebas poco consistentes desde el punto de vista lingüístico. En la mayoría no se ha determinado con exactitud la 
lengua de la cual proceden. Unas veces se anota "de origen incierto"; como en el caso de "tabaco", según la Real Academia; aunque Santamaría remite a Becerra, quien la clasificó como azteca y a Sopena como voz caribe; otras veces, la palabra ni siquiera está registrada en los diccionarios consultados.

Copalchí, según Santamaría, es un mayismo e indica que, en Costa Rica, a este árbol euforbáceo se le llama también Quezarrá. Matambú y Matambuguito, de acuerdo con Gagini, debe significar lugar poblado de matambas, propias de los lugares cálidos, pero Gagini no propone ninguna etimología. Burío fue clasificada por Agüero como una palabra de lengua indígena costarricense. En Honduras se le da ese nombre al mismo árbol y este aspecto la descarta como palabra de una lengua indígena costarricense.

Se espera ampliar la información y encontrar algún significado u origen en el trabajo de campo que se inicia este año, e incluirlo en el libro Toponimia de Guanacaste, o bien, en la investigación filogenética de Quesada Pacheco.

\section{TOPÓNIMO}

\section{Burío Blanco \\ Curubandé \\ Chumico}

Bongo

Bongo

Bongo

Botija

Brumel

Carao

Chepeñas

Chimpilo

Chipanzo

Chira

Chira

Chirca

Chiringa

Chiruta

Chora

Chumbulún

Chumbulún

Cóbano

Copalchí

Copalchí

Copalchí

Copalchí

Copalchí

Copalchí

Currupacho

\section{CARACTERÍSTICA}

Quebrada

Poblado

Poblado

Estero

Finca

Río

Poblado

Isla

Poblado

Cerro

Finca

Río

Cerro

Poblado

Estero

Quebrada

Poblado

Isla

Estero

Finca

Finca

Finca

Poblado

Poblado

Quebrada

Loma

Cerro

Finca

\section{MAPA BÁSICO}

Bahía Salinas

Curubandé

Matambú

Berrugate

Río Ario

Río Ario

Matambú

Punta Gorda

Talolinga

Cerro Brujo

Cerro Brujo

Matambú

Talolinga

Talolinga

Tempisque

Cañas

Río Ario

Garza

Tempisque

Monteverde

Abangares

Bahía Salinas

Bahía Salinas

Peñas Blancas

Peñas Blancas

Matambú

Matambú

Villarreal 


\section{TOPÓNIMO}

Gamalotal

Ipacaral

Juanilama

Juanilama

Juanilama

Juanilama

Malambo

Maquenca

Maquencal

Maquencal

Maquenco

Maquenco

Matambú

Matambú

Matambuguito

Munisango

Momollejo

Morote

Orotina

Picayal

Quirimán

Sacatipe

Sandal

Santolí

Sapoá

Sapoá

Tabaco

Tabaco

Tabaco

Tabaco

Taboga

Tacanis

Tacasolapa

Tacasolapa

Tirurí

Tilarán

Tranera

\section{CARACTERÍSTICA}

Poblado

Finca

Finca

Laguna

Poblado

Poblado

Cerro

Cerro

Finca

Poblado

Poblado

Poblado

Fila

Poblado

Poblado

Cerro

Río

Río

Quebrada

Quebrada

Río/Poblado

Finca

Río

Río

Río

Río

Quebrada

Quebrada

Poblado

Río

Hacienda

Cerro

Río

Quebrada

Hacienda

Poblado

Quebrada

\section{MAPA BÁSICO}

Cerro Brujo

Matambú

Belén

Murciélago

Belén

Monteverde

Belén

Cerro Azul

Río Ario

Cerro Azul

Cerro Azul

Garza

Matambú

Matambú

Matambú

Talolinga

Matambú

Matambú

Belén

Diriá

Cerro Brujo

Belén

Cerro Brujo

Murciélago

Peñas Blancas

Bahía Salinas

Cerro Azul

Cerro Azul

Diriá

Cerro Brujo

Cañas

Matambú

Matapalo

Villarreal

Cañas

Tilarán

Monteverde 


\section{Clasificación semántica de los nombres comunes procedentes de nombres indígenas}

Uno de los factores que determinan el nombre del topónimo es la interacción del medio ambiente, lo que se ha denominado en el modelo de análisis "componentes del ambiente". Este elemento es común a los hidrónimos, ecónimos y orónimos.

En el caso de los nombres comunes procedentes de las diferentes lenguas indígenas, entradas al castellano, estos corresponden a elementos de la flora y la fauna. De esta manera, cuando se seleccionan nombres de la flora o de la fauna, se toman aspectos típicos que demuestran sus preferencias culturales. En la toponimia indígena de Guanacaste hay muchos nombres que se refieren a árboles o plantas. Por ejemplo, con el nombre de Aguacate tenemos ríos, poblados y quebradas.

Otros nombres de árboles y plantas son Biscoyol, Bejuco, Bijagua, Burío Blanco, Caimito, Caimital, Cacao, Capulín, Ceiba, Chilamate, Chonta, Copalchí, Copal, Carao, Chirca, Henequenes, Cuajiniquil, Coyol, Espavel, Guachipelín, Guácimo, Guanacaste, Guapinol, Guayabo, Ojoche, Pochote, Tempisque, Jabilla, Jabillo, Jícaro, Jobo, Jocote, Juanilama, Mango, Maquenco, Nance, Pita, Quelites, Poroporo, Matambú, Guayacán, Santolí, Soncoyo, Tule, Zacate, Zapote, Papaturro, Nacascolo y Cacique.

Otros árboles, por su parte, producen frutos que son comestibles como el Caimito, Guapinol, Guayaba y Zapote. El Biscoyol es una palmera.

Otras veces no se selecciona el nombre del árbol o planta en forma aislada, sino toda la plantación. Así, el río, el cerro o el poblado llevan como nombre aquellos elementos que hay en abundancia. Por ejemplo, Achiotal designa un cerro, un estero y una quebrada; Bijagual un poblado y una quebrada, Caimital, poblado, quebrada y río; Capulinal, loma; Coyolar, cerros, fincas, haciendas, quebradas; Espavelar, fincas; Guaitilar, cerro y lomas; Guastomatal, poblados y quebradas; Guayabal, laguna, poblado; Madroñal, loma; Manglar, poblado; Maquencal, finca y poblado; Mozotal, cerro y poblado; Nancital, cerro, fila, loma y poblado; Ocotal, cerros y bahía; Ojochada, laguna; Ojochal, finca, llanos, poblado; Pital, finca, quebrada y poblado; Pochotada, finca y poblado; Tempatal, poblado; Yucal, loma; Zapotal, cerros, estero, finca, quebrada y río; Zapotillal, bahía y playa; Mojal, quebrada, finca y hacienda.

También se seleccionan productos derivados de plantas, tal es el caso de Huacal, poblado; Huacalito, cerro y finca; Guacalito, finca. Gagini registra la palabra solamente con "g", 'guacal', y se refiere a la vasija hemisférica hecha del pericarpio leñoso de ciertas calabazas, o más comúnmente de la fruta del jícaro.

Nambira, finca, es el nombre de una calabaza grande para llevar agua.

Chira, cerro y poblado, significa la espata del plátano. Según Sánchez, es la parte terminal del racimo del banano o del plátano, donde no crecen los frutos.

Eskameca, cerro. Según Mántica, se refiere a los cordeles de algodón. Del nahua ichcatl 'algodón' y mecatl 'cuerda'.

Otros nombres indígenas hacen referencia al lugar, es decir, describen alguna característica de éste.

Chincaca, quebrada. Según Mántica del nahua tzintli 'trasero' y cacayolli 'hueso saliente'. Hueso pequeño y protuberante con que termina la columna vertebral. Es interesante 
esta acepción pues el informante explicó que la quebrada lleva este nombre porque tiene poca agua y no le llega a un hombre ni a la chincaca.

Chinampas, cerro y poblado significa, según Morínigo, terreno donde se cultivan flores y verduras. Chinan + pa 'seto o cerca de cañas'.

Bagaces, según Gagini, es una palabra que parece provenir del cahita: baga 'caña o carrizo' + tzi 'lugar'. Así, Bagaces sería el lugar de las cañas o carrizos; no obstante, esta etimología no es segura. Quesada Pacheco propone como lengua de origen el corobicí.

Acoyapa, poblado, es según Mántica, lugar donde tuerce el río. Atl 'agua, río', colhua 'hombro,vuelta', pan 'lugar'.

Valle, citado por Mántica, dice: Acoyauh 'divisar desde lo alto', pan 'lugar'. 'En la Atalaya'.

Chahuite 'terreno fangoso'. Según Mántica del nahua Chiauitl 'sementera hecha en terrenos húmedos'. Valle, citado por Mántica lo deriva del nahua Zoquitl 'lodo, pantano'.

Talolinga, poblado: 'tembladero'. Según Mántica: del nahua tlalli 'tierra'; ollin 'movimiento' y co 'lugar'.

Para Berendt, citado por Mántica, talolinga es un terreno con agua donde se hunden las bestias o las reses.

Cuipilapa, poblado. Según Gagini se deriva de cuicuil - apan 'río de varios colores'.

Mántica lo refiere también a cuicuicani 'grillo' y apan 'río' por lo que puede significar 'río de los grillos'.

Pocosol, río. Para Gagini el nombre indígena era probablemente Pocauzol, del nahua popoca 'que humea' y del pipil auzol.

Sapoá, río. De acuerdo con Gagini, proviene de la raíz nahua tzapotl 'zapote' y atl 'agua'. Río de los zapotes; no obstante, se ubica en los topónimos de origen incierto o no determinado aún pues su etimología no es segura.

Tapezco, poblado y quebrada. Gagini y Mántica la derivan de tlapachtli 'cama, tablado, andamio, andas'. Especie de estera de cañas o varas. Cama de tablas, generalmente múltiple y de varios pisos, usual en los campamentos y demás dormitorios.

Nosara, punta. Tal vez del azteca nochli 'tierra' o tlalli 'tierra'. Quesada Pacheco propone como origen, la lengua chorotega.

Choluteca, finca. Según Mántica de cholua 'huir, correr' y tecatl 'gentilicio'. Pueblo que huye.

Tizate, río. Buesa Tomás lo deriva de tizatl 'greda, especie de tierra blanca'.

Por otra parte, un número muy reducido de nombres topónimos se refieren a la fauna. Por ejemplo los siguientes:

Chocuaca, finca. Según Gagini es un ave zancuda muy voraz que se encuentra casi siempre en las orillas de los ríos. Para Agüero es una voz imitativa.

Chocoyas, islote. Berend, citado por Mántica, explica que es una culebra verde, muy rápida. Agüero y Gagini registran la palabra Chocoyo como Chucuyo. Agüero la deriva del Pipil "chucuyo". Especie de perico de color verde ceniciento que vuela en bandadas y cae sobre las plantaciones de maíz dando gritos chillantes.

Coyote, cerro, playa, lomas, punta, río, quebrada, finca. Según Mántica del nahua coyotl. Especie de lobo que tiene el tamaño de un perro grande amarillento; anda en manadas, generalmente y sólo así ataca al hombre. Por las noches aúlla largamente. Es importante 
destacar que éste es el nombre correspondiente a la fauna que más aparece. Son nueve accidentes y una finca los que lo llevan.

Nandamojo, río. En la Villarreal aparece el nombre Andamojo para este río; debe tratarse de un error al levantar el mapa. De acuerdo con Quirós, el término es chorotega: nanda 'arroyo' y mojo 'ojoche'. Arroyo del ojoche.

Nandayure, río y cerro. Quirós la deriva de las raíces chorotegas, nanda 'arroyo' y yuri 'culebra'. Así, Nandayure es el arroyo de la culebra.

Cusuco: quebrada y laguna. Becerra, citado por Mántica, la deriva del nahua kuaitsok 'cabeza larga'. Membreño, citado por Gagini, cree que es voz de origen nahua y Berberena, también citado por Gagini, opina que es quiché. Coinciden en que Cusuco se refiere a un armadillo.

Guacamaya, finca. Según Gagini, la guacamaya es un ave de color verde. Agüero sólo registra la palabra, pero perteneciente a la fauna: planta que alcanza hasta tres metros de altu$\mathrm{ra}$, medio leñosa que tiene hojas laciniadas y de olor repugnante.

Guapote, hacienda y poblado. Mántica la deriva del nahua cuapozti 'despuntado'. Gagini opina que ni la etimología nahual del señor Ferraz, ni la etimología quiché que propone Barberena son aceptables, aunque no da otra etimología. El guapote es un pez de agua dulce, de trompa chata o "despuntada" como lo indica su etimología, explica Mántica.

Güis, quebrada y poblado. Mántica la deriva del nahua Cuixi o Cuixtli 'gavilán'. Voz onomatopéyica.

Guatusa, quebradas. Gagini propone dos etimologías del nahua quauhtocan, 'rata silvestre', o bien, quahtochtli, 'conejo de montaña'.

Mántica lo deriva del nahua huakik 'flaco' y tusann 'tusa' o de cuauhtla 'montaña, selva' y tusann 'tusa': tusa silvestre. Agüero, del nahua cuahuitl 'árbol' y tozan 'rata'. Roedor.

Gagini indica que es un roedor que habita en todos los países tropicales de América y del cual se conocen varias especies. La que habita en Costa Rica tiene el pelo corto y cerdoso, azafranado en el lomo y más oscuro en las extremidades, y los miembros posteriores más desarrollados que los delanteros.

Iguanita, finca y poblado. Reptil perteneciente a los saurios, de aproximadamente medio metro de longitud y de color verdoso. Tiene sobre el dorso, de la cabeza a la cola, una cresta escamosa y aserrada.

Jicote, bahía, lomas, laguna. Agüero y Mántica lo derivan del azteca xicotl 'abeja silvestre'. Panal de unas abejas negras y sin aguijón, generalmente construido en los huecos de troncos muy secos.

Pajuila, quebrada. Según Agüero y Gagini, del quechua pajui 'pavo'. Pavo silvestre de patas muy delgadas.

Nimboyores, río, cerro, finca. Según Quirós, debería ser Nimboyore, pues se deriva de las raíces chorotegas nimbu 'agua lluvia' y yori 'culebra, flor o pájaro'. El significado sería agua o lluvia de la culebra, de la flor o del pájaro.

Mojal, finca, hacienda y quebrada. Según Quirós es una raíz procedente del chiapaneco y su significado es ojoche. Aquí aparece con el sufijo -al que es abundancial y su significado sería 'abundancia de ojoches'. 
Piches, estero y poblado. Según Mántica proviene del nahua pixixi, pichichil o pixixil, pi 'coger' y shishitl 'amontonar, batir'. De acuerdo con Agüero el piche es un ave acuática, zancuda que se halla en las lagunas y los ríos de la vertiente del Pacífico.

Pizote, lomas. Agüero la deriva del nahua pozotl. Gagini del nahua pexotli 'zorro'. Cuadrúpedo algo semejante a una ardilla con el hocico largo y agudo. De color pardo.

Soncuán, quebrada. Según Mántica, del nahua zacuani 'amarillo'. Cierta avejita silvestre. Agüero la registra con ' $z$ ' zoncuán y se refiere a la avispa grande, negra, cuya miel es muy estimada, lo mismo que su cera.

Zompopa, cerro y quebrada. Agüero la deriva del azteca tzontli 'cabeza' y pold 'despectivo'. Hormiga grande, negra y de cabeza muy abultada.

Zompopero: multitud de zompopas.

Zonchiche: cerro. Según Agüero, del azteca tzontli 'cabeza' y chichitic 'rojo'. Buitre parecido al zopilote. Negro con las alas parduscas y la cabeza roja, sin plumas.

Zoncho, alto. Es apócope de Zonchiche.

Zopilota, quebrada y río. Según Agüero. avispa grande, negra, que hace el panal grande y alargado, de color gris claro. Su aguijón produce fuerte dolor y calentura. También existe una culebra llamada zopilota.

Zopilote, quebrada. Mántica la deriva del nahua tsotl 'suciedad'; piloa 'suspender'. Ave de rapiña, gallinazo. Abatirse el ave de rapiña para cazar.

En cuanto a los términos autóctonos, la mayoría proceden de la lengua huetar y ya han sido descritos por Quesada $(1990,1991)$.

\section{Estructuras gramaticales (morfología)}

Respecto de la morfología flexiva del español, los topónimos procedentes de nombres comunes son en su mayoría sustantivos singulares o plurales y no ofrecen mayor dificultad en su reconocimiento.

En cuanto a los morfemas de género, se mantiene la forma original de la palabra indígena; no obstante, algunas veces se establecen concordancias arbitrarias. Por ejemplo, Laguna Mica y Quebrada Mico; Cerro Maquenca y Poblado Maquenco; Quebrada Aguacata y Finca Aguacate; Bahía Pochote y Finca Pochota.

Respecto al uso de adjetivos, solamente aparecen las palabras Espavelosa como nombre de una laguna y Guayabalosa como nombre de una fila.

Es más importante referirse aquí a la morfología derivativa por cuanto presenta mayor variedad para su análisis. En este sentido, un elemento que se destaca en el corpus es el sufijo abundancial -al, con sus dos alomorfos -al, -ar. Así, tenemos palabras como Achiotal, Caimital, Capulinal, Huacal, Mojal, Coyolar, Espavelar, Guaitilar, Guastomatal, Guayabal, Ojochal, Pital, Maquencal, Manglar, Mozotal, Nancital, Ocotal, Icacal, Tempatal, Yucal, Zapotal, Jorcal, Turrujal, Zacatal(es).

De acuerdo con la regla fonética del español, el sufijo -ar aparece cuando en la palabra está presente el sonido $l$, tal es el caso de Coyolar, Espavelar y Guaitilar.

Otro sufijo abundancial, aunque aparece una sola vez, en dos nombres, es -ada. Ej. Pochotada y Ojochada. 
Sufijos que indican lugar los encontramos en los nombres Coyolera, lugar de coyoles, Coyotera, lugar de coyotes, Tucera, lugar o madriguera de tuzas.

También se encuentran en estos nombres sufijos diminutivos y despectivos.

$\begin{array}{ll}\begin{array}{l}\text { DIMINUTIVOS } \\ \text { Sufijos -it, -cito }\end{array} & \begin{array}{l}\text { DESPECTIVOS } \\ \text { Sufijo -ill }\end{array} \\ \text { Bejuquito } & \text { Jocotillo } \\ \text { Caimitalito } & \text { Ojochillal } \\ \text { Ceibita } & \text { Zapotillal } \\ \text { Coyolito } & \text { Zapotillo } \\ \text { Guacalito } & \\ \text { Huacalito } & \\ \text { Huaquitas } & \\ \text { Iguanita } & \\ \text { Jicarito } & \\ \text { Jobito } & \\ \text { Matambuguito } & \\ \text { Nosarita } & \\ \text { Talolinguita } & \\ \text { Orosilito } & \\ \text { Coyolarcitos } & \end{array}$

El uso de los diminutivos y de los despectivos permite darle nombre a un poblado o accidente geográfico que es más pequeño, o bien que está cerca del accidente o poblado que tiene el nombre en su forma simple.

En el caso de Zapotillal y Ojochillal se conjuga, además, el abundancial -al.

Especial atención merece el nombre Chilamo pues, aunque aparece solo una vez como nombre de un estero, presenta un fenómeno que no es común. Se trata del cambio analógico conocido como regresión. En este caso se supone la existencia de una complejidad morfológica inexistente y se crea una forma más simple de la que se habría formado la palabra que originalmente existía, de Chilamate se crea Chilamo.

\section{Conclusiones}

Del estudio realizado se puede concluir lo siguiente:

1. Los topónimos procedentes de nombres propios indígenas constituyen un grupo muy reducido y se refieren en su mayor parte a nombres de los caciques que gobernaban la comarca. Casi todos pertenecen a la lengua chorotega.

2. Los topónimos procedentes de nombres comunes provienen de diferentes lenguas indígenas, pero eso no significa que esos grupos anduvieron por esta provincia. Su presencia, co- 
mo ha sido ampliamente probado en otros estudios, se debe a la difusión que de estos vocablos hicieron los conquistadores y colonizadores españoles, al incorporarlos al léxico común de la lengua castellana. De esta manera, podemos encontrar nombres del nahua, azteca y de diferentes lenguas caribes.

3. Con respecto a los nombres autóctonos, como señala Quesada (1991: 93) en su libro El Español de Guanacaste, la escasa contribución chorotega en el enriquecimiento del léxico guanacasteco, se explica por el poco espacio de participación lingüística a que estuvo sometida la cultura chorotega durante la dominación española.

Es también muy reducida la presencia de nombres procedentes de otra lengua autóctona, como lo es la huetar. Pareciera que el término Orosí pertenece a la lengua corobicí; sin embargo, esto no ha sido constatado.

4. En relación con las preferencias culturales de los hablantes, para darles nombre a los accidentes geográficos y poblados o fincas, se destaca su inclinación por los nombres de árboles y plantas, ya sea en forma individual, o bien como colectivos o abundanciales. Muy pocos nombres se refieren a productos derivados de plantas. Lo mismo sucede con nombres que mencionan características del lugar. La presencia de nombres relacionados con la fauna también es limitada, aunque se puede ubicar en un segundo lugar, después de los nombres correspondientes a la flora.

5. En lo que atañe a las estructuras gramaticales, la morfología ofrece mayor riqueza de análisis, pues no aparecen nombres que constituyan frases o estructuras sintácticas complejas.

De la morfología flexiva, se destacan nombres singulares o plurales. Más interesante es el análisis de los topónimos según la morfología derivativa. Así encontramos gran cantidad de nombres que significan abundancia o colectividad de elementos. El sufijo que predomina en este sentido es - al. También aparecen nombres que presentan el sufijo -er, como 'lugar de'. El sufijo diminutivo -it también está presente, y al igual que otros nombres de Costa Rica, se refiere a un accidente geográfico que está cerca o que pertenece a un accidente o poblado que tiene el nombre en su forma simple y es más grande. Lo mismo sucede con el sufijo despectivo -ill, aunque en menor cantidad.

\section{Bibliografía}

Agüero Chaves, Arturo. 1962. El Español de América y Costa Rica. San José: Librería e Imprenta Atenea.

1996. Diccionario de Costarriqueñismos. San José: Ed. Sección de Publicaciones y extensión cultural de la Biblioteca Monseñor Dr. Víctor Manuel Sanabria, de la Asamblea Legislativa.

Arroyo, Víctor Manuel. 1953. "Nahuatismos y Nahuatlismos en Costa Rica". Tlatoani. 2a. Época, N.7. México. 
Buesa, Tomás Oliver y José Ma. Emguita Utrilla. 1992. Léxico del Español de América. Madrid: Ed. Colección MAPIRE.

Constenla U., Adolfo. 1994. Conferencia sobre la lengua huetar. Mimeografiada.

1984. "El huetar: observaciones sobre los materiales disponibles para su estudio y sobre las hipótesis en torno a sus afinidades lingüísticas". Revista de Filología y Lingüística. 10(2): 3-18.

Corominas, J. 1991. Diccionario crítico etimológico de la lengua castellana. Madrid: Gredos S.A.

De la Cruz, Vladimir et al. 1988. Historia General de Costa Rica. San José: Euroamericana Ediciones, S.A.

Ferrero Acuña, Luis. 1975. Costa Rica Precolombina: Arqueología, Etnografía, Tecnología. San José: Editorial Costa Rica.

Gagini, Carlos. 1917. Los aborígenes de Costa Rica. San José: Imprenta Trejos Hermanos.

1975. Diccionario de costarriqueñismos. San José: Editorial Costa Rica.

Gamboa, Ofelia. Entrevista personal. 14 de febrero de 1997.

Malaret, Augusto. 1946. Diccionario de Americanismos. Buenos Aires: Emecé.

Mántica, G. 1973. El habla de Nicaragua. San José: EDUCA.

Meléndez, Carlos. 1974. Viajeros por Guanacaste. San José: Ministerio de Cultura, Juventud y Deportes.

1977. Costa Rica: Tierra y Poblamiento de la Colonia. San José: Editorial Costa Rica.

1978. Costa Rica vista por Fernández de Oviedo. San José: Ministerio de Cultura, Juventud y Deportes, Departamento de Publicaciones.

Morínigo, Marcos A. 1966. Diccionario Manual de americanismos. Buenos Aires: Muchnik eds.

Neves, Alfredo. 1975. Diccionario de Americanismos. Buenos Aires: Editorial Sopena.

Pittier, Henri. 1978. Plantas usuales de Costa Rica. San José: Editorial Costa Rica. 
Quesada Pacheco, Miguel A. 1990. El Español Colonial de Costa Rica. San José: Editorial de la Universidad de Costa Rica.

1991. El Español de Guanacaste. San José: Editorial de la Universidad de Costa Rica.

1990. "La lengua huetar". Estudios de lingiüística chibcha. San José: Editorial de la Universidad de Costa Rica.

Entrevista personal. Enero-febrero de 1997.

Quirós, Juan Santiago. 1986. "Etimología de los nombres 'Chorotega', 'Mangue' y 'Diriá'. Revista de Filología y Linguiística. XII (1): 151-2.

1987. "Términos chorotegas en la toponimia guanacasteca". Revista Letras. 15, 16, 17.

Real Academia Española. 1992. Diccionario de la Lengua Española. Madrid: Editorial Espasa-Calpe.

Robelo, Cecilio. s.f. Diccionario de Aztequismos. México: Ediciones Fuente Cultural.

Santamaría, Francisco. 1942. Diccionario general de americanismos. Méjico D.F: Editorial Pedro Robledo.

Secretaría de Gobernación. 1924. Guanacaste. Libro Conmemorativo del Centenario de la Incorporación del Partido de Nicoya a Costa Rica. 1824-1924. San José: Imprenta María U. de Lines.

Sopena, Ramón. 1982. Americanismos. Diccionario ilustrado. Barcelona: Editorial Sopena S.A.

Vega Cortés, Romain. Entrevista personal. 14 de febrero de 1997. 